\title{
Emission inventory for urban transport in the rush hour: application to Seville
}

\author{
J. Racero, M. Cristina Martín, I. Eguía \& F. Guerrero \\ School of Engineering, University of Seville, Spain
}

\begin{abstract}
Energy and transport are indispensable ingredients for economic and social development. At the same time conventional forms of energy production, distribution and consumption as well as sustainable transport and mobility patterns are linked to environmental degradation.

The goal of the work is to develop a decision support system able to help local administrators in reducing the impact of air pollution due to urban traffic. The method designed is a framework, which included a transportation planning tool and a comprehensive model to estimate pollutants emissions. The hourly traffic flow data is obtained from transportation planning, and the emission model integrated is based on COPERT methodology. Detailed traffic data have been collected and analyzed from the city of Seville to test the methodology.

Keywords: CORINAIR, emission inventory, traffic assignment model, transportation planning.
\end{abstract}

\section{Introduction}

Among the sources of air pollution, road traffic is widely recognised to be the most important and increasing source. Carbon dioxide $\left(\mathrm{CO}_{2}\right)$ and water vapour $\left(\mathrm{H}_{2} \mathrm{O}\right)$ are the most significant transport emissions to the atmosphere. When combustion is incomplete, fuel is oxidised to carbon monoxide (CO) with some volatile hydrocarbons. Impurities such as sulphur are oxidised mostly to sulphur dioxide $\left(\mathrm{SO}_{2}\right)$ or to sulphate during the combustion process. And finally, at high combustion temperatures, nitrogen is oxidised to nitric oxide (NO) and small quantities of nitrogen dioxide $\left(\mathrm{NO}_{2}\right)$ or nitrous oxide $\left(\mathrm{N}_{2} \mathrm{O}\right)$. UNECE/EMEP [7] estimated road traffic emissions to account for about $54 \%$ of CO emissions, $47 \%$ 
of $\mathrm{NO}_{\mathrm{x}}$ emissions and $27 \%$ of hydrocarbon emissions within the European Union.

One of the main applications of road traffic emission estimation is to build an atmospheric emission inventory, a collection of data related to the emissions of pollutants into the air, often with spatial resolution [3]. As governments have the ability to influence the reduction of emissions by the application of different strategies, such as improved fuels and vehicle technology [4], then the emission inventories are important for helping in the identification of zones with similar pollution problems and for the analysis and evaluation of different strategies, which is necessary prior to any implementation. They are also important as input data for atmospheric dispersion models. Finally, these inventories are essential to quantify the population exposed to the pollution levels measured by an air quality monitoring station.

In the last decade, the European Environment Agency [7] has developed some air pollution projects. The aim of those projects was to collect, maintain, manage and publish information on emissions into the air from all relevant sources of environmental problems. All these projects are compiled using the CORINAIR (CORe Inventory AIR) methodology [7]. The pollutant emissions from road transport depend on driving speed and vehicles types, the estimation of those emissions need traffic related data, including the transport activity and driving conditions per category of vehicle.

In the context of an integrated modelling approach, emission models can be considered as tools allowing the calculation of air pollution emissions from a traffic network. Two approaches can be adopted to quantify the atmospheric emissions: the bottom-up and the top-down methodologies [19].

The bottom-up approach is the usual and detailed way to obtain a traffic emission inventory. The emission inventories are obtained directly by measurement of each individual source [13,17]. Total emissions for a geographical area can be obtained by the aggregation of the individual ones. To estimate the urban traffic inventory, the bottom-up approach starts with the calculation of the traffic flow for each road segment using a traffic model based on origin-destination surveys or traffic survey/counters [1]. Then, the results are used as input data of an emission model to finally obtain the estimates emissions for every road of the urban area studied.

The top-down approach starts with aggregated data of total pollution activities throughout the whole geographical area. Spatial desegregation is then performed by assuming that local emissions are proportional to same variable. This approach is usually used to build national emissions inventories, for example, using total petrol national sales as input data, average emission of pollutant per litre of petrol consumed and per category of vehicles, and finally population density.

COPERT-Computer Programme to Estimate Emissions from Road Traffic[14] is the mathematical model recommended by the European Environment Agency for the compilation of CORINAIR emission inventories. COPERT is based on a database with information on the national automotive fleet, speeddependent emission functions or average speed for each type of vehicle. 
In this paper a bottom-up method to estimate the air pollutant and greenhouse gas emissions from road transport in urban areas is proposed, integrating the COPERT methodology into an assignment traffic model. An application to the city of Seville is also showed.

\section{Description of the methodological approach}

The emission inventory developed is based on a bottom-up methodology where the pollutants emissions are calculated by a peak day's hour. In this work, air pollutant emission for urban transport has been calculated using a transportation planning software, integrated with EMEP/CORINAIR guide [8]. Using this method, the traffic control operators and authorities can evaluate strategic rules to improve the pollutants emission previous to their implementation.

In this study, an assignment model is applied to forecast the traffic flow and speed in the street. The assignment model is part of classic transport model, which does not solve transport problems, but they can be used within a decision process adapted to the chosen decision-making [15].

The methodology proposed is divided into two phases. The first phase is oriented to forecast the traffic flow and the average speed on the streets or links (Fig. 1). The second phase consists of estimating the pollutants emission classified by vehicles categories (Fig. 2). The traffic flow forecasting is based on solving the equilibrium traffic assignment problem. The assignment model input data are:

- A detail description of road traffic network

- The traffic demand characteristics, expressed in term of origin-destination (O-D) matrix of road vehicles. This matrix shows the hourly mobility between zones. The matrix is updated by a calibration method and traffic surveys/counters located in the network.

One of mainly different between Top-Down and Bottom-Up methods is the speed calculation. The emission equations use the speed as input data, in the most cases the speed is obtained by surveys in specific location and the model applied an average speed for all network. The assignment model resolution provides, by the cost function application, the average speed on each link, that it is more detailed than surveys estimation.

\subsection{Traffic assignment model}

The assignment model used to forecast the traffic flow is an extension of Beckman's model [2]. This is a non-linear model, based on the Wardrop [18] equilibrium conditions and can be solve by the Frank-Wolfe algorithm [10]. This algorithm allows the estimation of traffic flows within each link of the road network from the knowledge of the network features and traffic demand.

The Frank-Wolfe algorithm computes, by iterative form, the minimum path between all pair Origin-Destination zones and then it assigns trips (OriginDestination matrix) to the links. In each step the algorithm obtains an optimal factor, which is used to distribute the trips on all paths. The trip time on the links 
is calculated by applying parametric cost/time functions. All links have associated a cost/time function that depends on links characteristics and traffic flow. The functions have a saturation level that it limits the traffic flow. Finally, with the traffic flow on links, the delay functions are applied in each link to obtain the average speed.

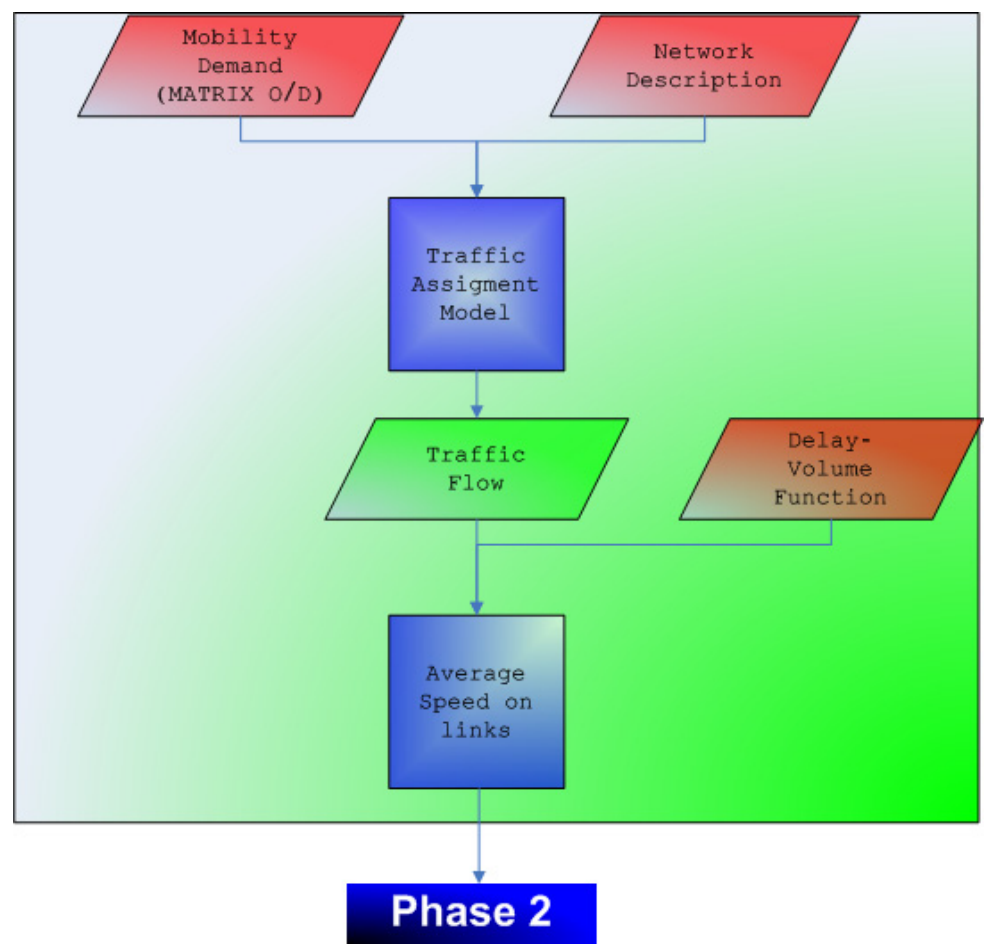

Figure 1: $\quad$ Structure of methodology, phase 1.

\subsection{Pollutant emission model}

The second phase is oriented to forecast the pollutants emission on all links, based on the average speed calculated in previous phase and using the mathematical equations proposed by COPERT which depends only on the vehicle speeds. The expressions for emissions factors provided in COPERT are based on analysis of a very large amount of data from several European vehicles. EMEP/CORINAIR guide classifies the vehicles in categories according to the type of vehicle, class and legislation. Different pollutants equations are defined for each category [6]. Then, the work focuses on statistical analysis of vehicle fleet. The goal is to compose a percentage or ratio tree that shows the composition of each category.

The final forecast is calculated for each link. It depends on the traffic flow, transport mode allowed and percent of vehicles categories. 


\section{Application}

The methodology has been applied from $8 \mathrm{pm}$ to $9 \mathrm{pm}$ in the city and metropolitan area of Seville.

The first phase, applied in Seville, can be divided in three tasks: updating the traffic network, obtaining the traffic flow and calculating the average speed. The first one is to update the traffic network using transportation software. TRAMOS is a software developed for this study (an integrated Geographical Information System and Transportation planning, [16]) and used to specify the data associate to each link: transport mode allowed, length, number of lanes and the delayvolume function. In this study about 30 types of functions are used, which depend on typology of the street or avenue, pavement, saturation level, width and speed limit. A volume-delay function has been assigned to each link according to its own features.

\section{Phase 1}

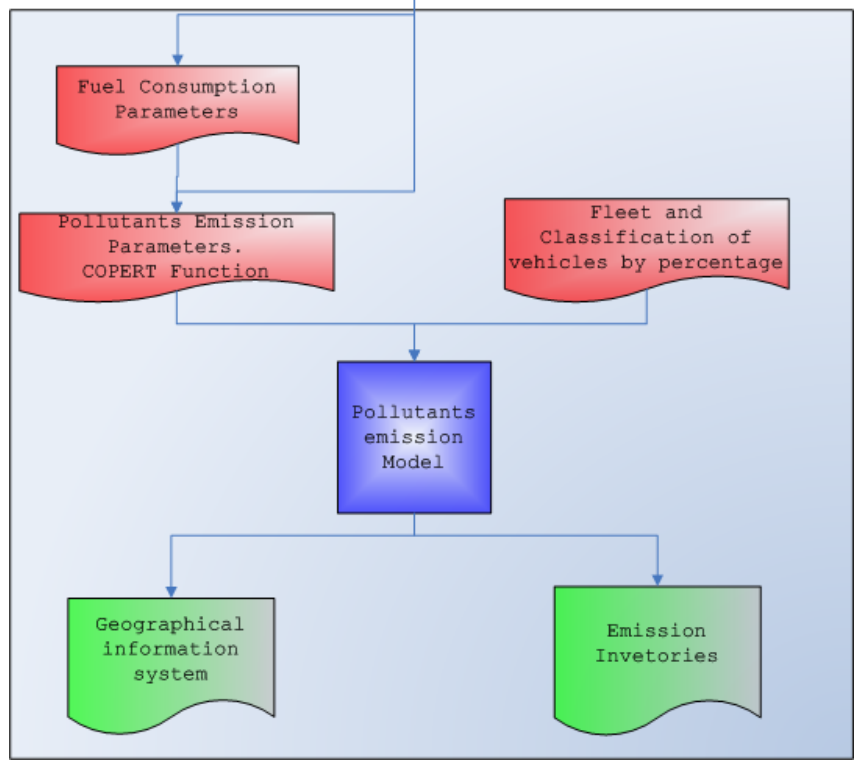

Figure 2: $\quad$ Structure of methodology, phase 2.

The hourly mobility demand between each zone in the study area is grouped in the Origin-Destination Matrix. The Matrix data is obtained from the Transport Planning Studies and it is updated by sensor counters located in some links. In resume, the city model presents about 5000 links, 1200 nodes and 220 zones and the mobility are from 9:00h to 10:00h. Once traffic demand data are provided and the network is updated, it is possible to simulate the traffic flow behaviour within each link of the network. TRAMOS includes a traffic assignment algorithm, which implements a Frank-Wolfe Algorithm. The input data 
necessary to run the algorithm are the Origin-Destination matrix (Updated) and the network characteristics. Once traffic flows over each links that have been assigned by the traffic model, it is possible to evaluate their relative mean speed by delay-volume function. The average speed on links is calculated by applying the expression (1):

$$
\text { Speed }_{1}=\text { Length }_{1} / \mathrm{F}_{1}(\mathrm{I})
$$

where Speed $_{l}$ is the average speed estimate in the link 1, Length $h_{l}$ is the length of the link and $F_{l}(I)$ is the volume-delay function assign to link l. I parameters are the link attributes as lanes, length and traffic flow.

The next phase is centred on classifying the vehicles into categories. The vehicle fleet information is colleted from vehicle registration in the general traffic administration [5].

The statistical analysis studies vehicles based on engine size, fuel type, emission control technology (registration year) and vehicle class. In each case, this is achieved by firstly determining the percentage according to the total vehicles, from statistical source data (Table 1). Then the percentage tree is determined, and the last level shows the category percentage in relation to total, and the intermediate node is the relative percentage in the category. In Seville, the percentage tree has 79 categories.

Table 1: Vehicle percentage regarding total.

\begin{tabular}{|l|l|l|l|l|l|}
\hline Motorcycle & Car & $\begin{array}{l}\text { Van } \\
\text { Truck }\end{array}$ & Bus & $\begin{array}{l}\text { Industrial } \\
\text { Vehicles }\end{array}$ & $\begin{array}{l}\text { Others } \\
\text { Vehicles }\end{array}$ \\
\hline 0,0605 & 0,7473 & 0,1632 & 0,0023 & 0,0067 & 0,0199 \\
\hline
\end{tabular}

The next task in this phase is to apply the emission model. The model is based on COPERT which formulations have been integrated into TRAMOS. The estimation process is an iterative procedure, where on each link the length, the average speed and the traffic flow is used to estimate the pollutants emission according to the expression described in the equation (2):

$$
E_{l p}=\sum_{i=1}^{N} P_{i} \times \delta_{i l} \times T_{l} \times F_{p i}\left(v_{l}\right) \times \text { Length }_{l} \quad \forall l, p
$$

$E_{l p}$ : Emission of $\mathrm{p}^{\text {th }}$ pollutant in a time period (measured in grams/hour).

$P_{i}$ : Category percent of $\mathrm{i}^{\text {th }}$ category

Length $_{l}$ : Length of the link 1 (kilometre)

$N$ : Number of categories

$T_{l}$ : Traffic flow on the link (vehicles/hour)

$\delta_{i l}$ : Link Parameter. 1 if the $\mathrm{i}^{\text {th }}$ category is allowed on the $\mathrm{1}^{\text {th }}$ link and 0 other case. $v_{l}$ : Average speed in the $1^{\text {th }}$ link (kilometre/hour).

$F_{p i}$ : Emission equation of $\mathrm{p}^{\text {th }}$ pollutant in the $\mathrm{i}^{\text {th }}$ category (gram/kilometre).

The emission equation is described in CORINAIR guide. The guide presents a set of equations according to the pollutant and speed to estimate road traffic emission. The inventory emission is obtained in disaggregated form (by links and categories, Table 2), the results can be shown in aggregated form, and for example inventories are obtained according to the categories (Table 3 ). Then, the 
Table 2: $\quad$ A category emission in a link $(\mathrm{g} / \mathrm{h})$.

\begin{tabular}{|c|c|c|c|c|c|c|}
\hline Category & Class & Legisl. & NOx & $\mathrm{CO}$ & $\mathrm{CO}_{2}$ & $\mathrm{~N}_{2} \mathrm{O}$ \\
\hline \multirow{9}{*}{$\begin{array}{c}\text { Private } \\
\text { car }\end{array}$} & \multirow{3}{*}{ Gas $<1,61$} & Bef. 1985 & 3,5 & 130,4 & 1084,7 & 15,3 \\
\hline & & $\ldots$ & $\ldots$ & $\ldots$ & $\ldots$ & $\ldots$ \\
\hline & & 1998-2002 & 0,6 & 18,20 & 1068,8 & 229,09 \\
\hline & \multirow{3}{*}{$\begin{array}{c}\text { Gas } \\
1,61-2,0\end{array}$} & Bef. 1985 & 5,0 & 99,54 & 1024,8 & 11,71 \\
\hline & & $\ldots$ & $\ldots$ & $\ldots$ & $\ldots$ & $\ldots$ \\
\hline & & 1998-2002 & 0,5 & 14,48 & 1105,8 & 174,61 \\
\hline & \multirow{3}{*}{ Gas $>2,01$} & Bef. 1985 & 0,9 & 21,97 & 280,14 & 2,58 \\
\hline & & $\ldots$ & $\ldots$ & $\ldots$ & & $\ldots$ \\
\hline & & 1998-2002 & 0,1 & 4,43 & 319,11 & 38,57 \\
\hline
\end{tabular}

Table 3: $\quad$ Total emissions by category.

\begin{tabular}{|c|c|c|c|c|}
\hline Categories & $\begin{array}{c}\mathrm{NOx} \\
{\left[\mathrm{Kg} \mathrm{NO}_{2} / \mathrm{h}\right]}\end{array}$ & $\begin{array}{c}\mathrm{CO} \\
{[\mathrm{Kg} / \mathrm{h}]}\end{array}$ & $\begin{array}{c}\mathrm{CO}_{2} \\
{[\mathrm{Kg} / \mathrm{h}]}\end{array}$ & $\begin{array}{c}\mathrm{N}_{2} \mathrm{O} \\
{[\mathrm{Kg} / \mathrm{h}]}\end{array}$ \\
\hline $\begin{array}{c}\text { Car gasoline }<1.61 \\
\text { before } 1985\end{array}$ & 65,657 & 1364,829 & 12971,420 & 291,911 \\
\hline$\ldots$ & $\ldots$ & $\ldots$ & $\ldots$ & $\ldots$ \\
\hline $\begin{array}{c}\text { Car gasoline }<1.61 \\
1998-2002\end{array}$ & 12,140 & 204,310 & 18355,730 & 3547,516 \\
\hline $\begin{array}{c}\text { Car gasoline 1.6 1 -2.0 1 } \\
\text { before 1985 }\end{array}$ & 125,882 & 1041,356 & 11722,904 & 222,726 \\
\hline$\ldots$ & $\ldots$ & $\ldots$ & $\ldots$ & $\ldots$ \\
\hline $\begin{array}{c}\text { Car gasoline }>2.01 \\
\text { before 1985 }\end{array}$ & 19,361 & 229,836 & 3112,539 & 49,158 \\
\hline$\ldots$ & $\ldots$ & $\ldots$ & $\ldots$ & $\ldots$ \\
\hline $\begin{array}{c}\text { Car gasoline }>2.01 \\
1998-2002\end{array}$ & 2,617 & 54,419 & 5079,652 & 597,367 \\
\hline Car diesel $<2.01$ & 152,844 & 202,209 & 54176,564 & 7380,179 \\
\hline$\ldots$ & $\ldots$ & $\ldots$ & $\ldots$ & $\ldots$ \\
\hline $\begin{array}{c}\text { Motorcycles } \\
>74 \text { c.c. }\end{array}$ & 3,912 & 194,500 & 18643,038 & 125,161 \\
\hline Total (T/h) & 4,103 & 10,325 & 416,367 & 24,367 \\
\hline
\end{tabular}

Table 4: $\quad$ Total emissions in Seville between $8 \mathrm{~h}-9 \mathrm{~h}$.

\begin{tabular}{|c|c|c|c|c|c|}
\hline $\begin{array}{c}\mathrm{NOx} \\
{[\mathrm{t} \mathrm{NO} 2 / \mathrm{h}]}\end{array}$ & $\mathrm{CO}[\mathrm{t} / \mathrm{h}]$ & $\begin{array}{c}\mathrm{COV} \\
{[\mathrm{t} \mathrm{Ch} 1.85 / \mathrm{h}]}\end{array}$ & $\begin{array}{c}\mathrm{SO} 2 \\
{[\mathrm{t} / \mathrm{h}]}\end{array}$ & $\mathrm{CO}_{2}[\mathrm{t} / \mathrm{h}]$ & $\begin{array}{c}\mathrm{N}_{2} \mathrm{O} \\
{[\mathrm{t} / \mathrm{h}]}\end{array}$ \\
\hline 4,103 & 10,325 & 2,479 & 0,068 & 416,367 & 24,367 \\
\hline
\end{tabular}



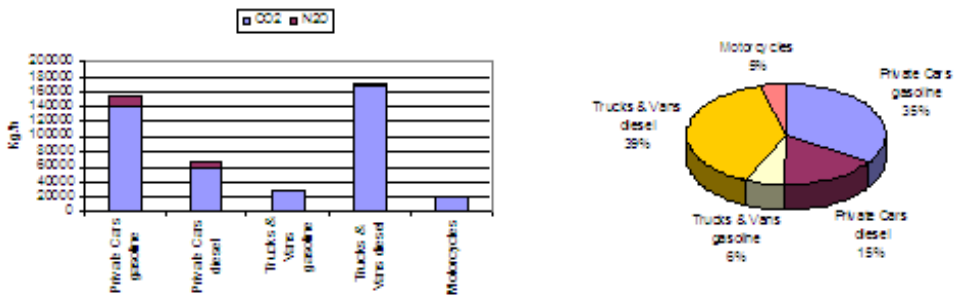

Figure 3: Greenhouse gas emission.

emissions could be aggregated to obtain global results (Table 4). Also, analysis of each category and pollutants group could be calculated (Fig. 3) and total emission can be obtained. Finally, the link data emissions (aggregated or disaggregated) could be used by the traffic control operators to analyze and compare different strategies.

An aggregate analysis (Fig. 3) shows that the private car is the main greenhouse gases contributor in the metropolitan area (50\%) at 8-9 a.m. A detail link analysis can be used to design strategies to improve the environmental impacts. Although, the number of cargo vehicle is low their emission are very high (about $40 \%$ of total of greenhouse gases).

\section{Validation}

The Atmospheric Emission Inventory Guidebook [11] provides a general overview of verification procedure showing the tasks that can be applied to demonstrate the applicability and reliability of emission inventory data. The validation method used is based on the precision of the emission factors derived from COPERT [12]. The methodology has been compared with software last version of COPERT (COPERT IV) to probe that the new methodology is equivalent to disaggregate the EMEP/CORINAIR guide. The relation among methods is compared to probe that changes are minimal.

Table 5: $\quad$ Comparison with COPERT.

\begin{tabular}{|c|c|c|c|}
\hline & $\begin{array}{c}\mathrm{NOx} \\
(\mathrm{t} \mathrm{NO} 2 \cdot \mathrm{h}-1)\end{array}$ & $\begin{array}{c}\mathrm{CO} \\
(\mathrm{t} \cdot \mathrm{h}-1)\end{array}$ & $\begin{array}{c}\mathrm{CO}_{2} \\
(\mathrm{t} \cdot \mathrm{h}-1)\end{array}$ \\
\hline (A) COPERT & 3,95 & 15,025 & 503775 \\
\hline (B) New Approx. & 4,103 & 10,325 & 416,367 \\
\hline Relation (A/B) & 0,96 & 1,45 & 1,20 \\
\hline
\end{tabular}

The new methodology proposed uses the same vehicles categories as COPERT IV. The average speed used as input data in COPERT IV is the diary mean. This speed is different according to the zone. The comparison shows the differences between the COPERT IV software and the estimation using the new local methodology (Table 5). The ratios between the bottom-up method and top- 
down method (COPERT) vary in the range $0.8-1.45$ depending on the pollutants considered. The approximation indicates that both methods are similar, only to emphasize that the bottom-up method is a bit more accurate than Top-Down method.

\section{Conclusion}

A new methodology for estimating, predicting and evaluating air pollution due to road traffic in urban areas has been proposed.

The main contribution of the methodology is that it makes an integrated system for use by the local administration in order to forecast alert pollutants levels in urban atmosphere and to analyse and evaluate local and global strategies before applying them in local areas.

This method is a useful evaluator tool in the context of transport planning and local air quality management. The policy advisory tool will aid Local Authorities in trying to asses the implications of their traffic and pollution management policies and will assist in the integration of these activities within air quality management strategies.

\section{Acknowledgements}

This work is has been developed into the project "Estimation and improvement methods for power efficiency and environmental air quality in ATMS-ATIS systems" subsidized by the Public Works Ministry with number T30/2006.

\section{References}

[1] Baldasano, J. Guidelines and Formulation of an Upgrade Source Emission Model for Atmospheric Pollutants. 1998. Air Pollution Emissions Inventory.

[2] Beckman, M. J., C. B. McGuire, and C. B. Wisten. 1956. Studies in the Economics of Transportation. Ed: New Haven: Yale University Press.

[3] Bellasio, R., Bianconi, R., Corda, G., Cucca, P., 2007. Emission inventory for the road transport sector in Sardinia (Italy). Atmospheric Environment 41 (4), 677-691.

[4] Covile R.N., Hutchinson E.J. and Warren R.F. 2001. The transport sector as a source of air pollution. Atmospheric Environment, 35,1537-1565.

[5] DGT.2003. Dirección general de tráfico. Statistic vehicle registration.

[6] Eggleston H.S., Gaudioso D., Gorissen N., Jourmard R. Rijkeboer R.C., Samaras Z. and Zierock K.H. 1992. CORINAIR Working Group on Emission Factors for Calculating Emissions from Road Traffic. Volume 1: Methodology and Emission Factors.

[7] European Environment Agency (EEA) 2004. Environmental signals 2004. European Environment Agency. Copenhagen. ISBN: 92-9167-669-1 
[8] European Environment Agency (EEA) EMEP/CORINAIR, 1999. Atmospheric Emission Inventory GuideBook.

[9] EPA. 2002. User's Guide to MOBILE6.0. Mobile Source Emission Factor Model. EPA420-R-02-001. United States Environmental Protection Agency.

[10] Frank, M. and P. Wolfe. 1956. An algorithm for quadratic programming. Naval research logistics quarterly 3 (1-2), 95-110.

[11] Mc Innes G. 1996, Atmospheric emission inventory guide book, A joint EMEP/CORINAIR Production, EEA, B710/9-11, Copenhagen.

[12] Mensink C. 2000 Validation of urban emission inventories. Environmental Monitoring and Assessment 65: 31-39.

[13] Negrenti E., 1995, Bottom-up traffic Emission models, COST 319. Estimation of pollutant emissions from transport. Brussels.

[14] Ntziachristos L. and Samaras Z. 2000. COPERT III Version 2.1: Methodology and emission factors, European Environmental Agency.

[15] Ortuzar J, Willumsen L., 2004. Modelling Transport. Ed: John Wiley \& Sons. ISBN 0-471-86110-3. pp. 23-31

[16] Racero J. 2003. Transportation planning and simulation techniques to analysis traffic problems in urban context, thesis. University of Seville.

[17] Teng H., Yu L., and Qi Y., 2002. Statistical microscale emission models incorporating acceleration and deceleration, in Proceedings of the 81st Annual Meeting of the Transportation Research Board, Washington D.C.

[18] Wardrop, J. G. 1952. Some theoretical aspects of road traffic research. Proceedings of the Institution of Civil Engineers, Part II, Vol. 1, 325-378.

[19] Zachariadis, T. and Z. Samaras, 1995, Comparison of microscale and macroscale traffic emission estimation tools: DGV, COPERT and KEMIS, COST 319 - Estimation of pollutant emissions from transport, Preproceedings of the workshop on 27-28 November 1995 at ULB - Brussels. 